\title{
IMPLEMENTASI KOMPARASI ALGORITMA KLASIFIKASI MENENTUKAN KELULUSAN MATA KULIAH ALGORITMA UNIVERSITAS BUDI LUHUR
}

\author{
Nahot Frastian \\ Program Studi Informatika, Universitas Indraprasta PGRI \\ nahotfrastian@gmail.com
}

\begin{abstract}
Abstrak
Implementasi komparasi algoritma memberikan inovasi dan motivasi mahasiswa setiap semester perkuliahan. Mahasiswa Universitas Budi Luhur yang mengikuti semua kegiatan proses belajar di kelas atau tatap muka setiap mata kuliah akan lebih punya peluang lulus dibanding dengan mahasiswa yang jarang hadir, beberapa penilaian dosen terhadap Kelulusan mata kuliah antara lain masalah kehadiran, tugas, ujian tengah semester dan ujian akhir semester. penelitian membuat algoritma yang sesuai untuk menentukan lulusan mata kuliah pada mahasiswa, peneliti ini akan menggunakan data mining teknik klasifikasi dengan 3 metode Algoritma klasifikasi antara lain Algoritma C4.5 (decision tree), Nä̈ve Bayes, dan Random Forest dengan label result tidak lulus dan lulus. Hasil penelitian menguji dan melakukan dengan digunakan dataset yang sama pada ke 3 algoritma melalui perbandingan mendapat nilai $A U C$ dan Confusion Matrix, memperoleh nilai Area Under Curve (AUC) sebesar 2.000 dari model Nä̈ve Bayes, sedangkan nilai Accuracy atau Confusion Matrix yang terbesar terdapat pada algoritma C4.5 (decision tree) dengan nilai sebesar 98.88\%. Dengan demikian, mata kuliah algoritma memberikan penilaian pada algoritma C4.5 (decision tree). Implementasi komparasi algoritma klasifikasi menetukan kelulusan mata kuliah algoritma di Universitas Budi Luhur.
\end{abstract}

Kata Kunci : Implementasi, komparasi algoritma, data mining klasifikasi, Algoritma C4.5

\begin{abstract}
The implementation of algorithm comparison provides innovation and motivation to students every semester of lecture. Budi Luhur University students attending all learning activities or face-to-face meetings in the classroom for each subject will have more chance to pass compared with those who rarely present. Some lecturer's evaluation to give a pass in subject include attendance, assignment, midterm examination and final examination. In this research, when creating an appropriate algorithm to determine the pass in subject of the students, this researcher will use data mining classification technique with 3 methods of Classification algorithm, namely Algorithm C4.5 (decision tree), Naïve Bayes and Random Forest with result labels of fail and pass. The results of the research tested by using the same dataset on the 3 algorithms through comparison get the value of AUC and Confusion Matrix, obtain the value of Area Under Curve (AUC) of 2,000 from the Naïve Bayes model, while the greatest Accuracy or Confusion Matrix values is in the C4.5 algorithm (decision tree) with a value of 98.88\%. Thus, the algorithm subject gives an assessment of the C4.5 algorithm (decision tree). The implementation of classification algorithm comparison determines a pass in algorithm subject at Budi Luhur University.
\end{abstract}

Keywords : Implementation, algorithm comparation, data mining classification, Algorithm C4.5

\section{PENDAHULUAN}

Implementasi komparasi algoritma klasifikasi lulus kuliah tepat waktu bagi mahasiswa yang sedang mengenyam pendidikan tinggi merupakan sebuah target yang harus dicapai. Hal ini tergantung pada individu mahasiswa itu sendiri. Berbicara masalah lulus kuliah tidak terlepas dari tahapan kelulusan seluruh mata kuliah yang diambil setiap semesternya. Faktor utama penyebab lulus dan tidaknya mata kuliah adalah melalui penilaian dosen mata kuliah terhadap mahasiswanya, bagi mahasiswa yang mengikuti semua kegiatan 
proses belajar di kelas atau tatap muka setiap mata kuliah akan lebih punya peluang lulus dibanding dengan mahasiswa yang jarang hadir, karena lulus dan tidaknya mata kuliah ditentukan oleh beberapa kriteria penilaian antara lain nilai kehadiran dan nilai tugas, nilai ujian tengah semester dan nilai ujian akhir semester. Setiap mahasiswa lulus atau tidak lulus mata kuliah, dibutuhkan penerapan teknologi yang serba sistematis dan diharapkan lebih baik dari pola sebelumnya. Dalam memperoleh algoritma klasifikasi yang terbaik, maka dibutuhkan beberapa penerapan metode algoritma. Dalam makalah ini metode algoritma klasifikasi yang akan digunakan menjadi Algoritma C4.5 (decision tree), naïve bayes, dan Random Forest. Begitu banyak teknologi dan metode algoritma untuk menjadi pengolah data (data mining), namun pada kenyataannya masih banyak dosen yang belum menerapkan teknologi dan metode algoritma, sementara data tersebut dan menjadikan metode ini penting dan bermanfaat.

Pada penelitian ini, fokus utama data mining yang akan dibahas adalah klasifikasi, dimana algoritma menjadi untuk klasifikasi dataset adalah Algoritma C4.5 (decision tree), Nä̈ve Bayes, dan Random Forest. Sementara data training menjadi data penilaian mahasiswa terhadap mata kuliah Algoritma pada universitas Budi Luhur, berikut kriteria penilaian kelulusan mata kuliah antara lain nilai kehadiran dan tugas, ujian tengah semester dan nilai ujian akhir semester. Data penilaian ini terdiri dari 87 record dengan tujuan akhir adalah keputusan lulus atau tidak terhadap mata kuliah tersebut.

Data mining adalah istilah yang diciptakan untuk menggambarkan proses pergeseran melalui database besar untuk mencari pola yang menarik dan sebelumnya tidak diketahui [1].
Klasifikasi adalah salah satu peran utama dalam data mining. Klasifikasi adalah tipe analisis data yang dapat membantu orang menentukan kelas label dari sampel yang ingin di klasifikasi [2].

Dalam klasifikasi kita dapat menentukan orang atau objek kedalam suatu kategori tertentu, contoh untuk masalah klasifikasi adalah menentukan apakah mahasiswa "lulus" atau "tidak lulus" terhadap mata kuliah tertentu. Informasi tentang mahasiswa sebelumnya digunakan sebagai bahan untuk melatih algoritma dalam mendapatkan rule atau aturan.

Salah satu tujuan klasifikasi adalah untuk meningkatkan kehandalan hasil yang diperoleh dari data [5].

C4.5 adalah algoritma yang memiliki input berupa training samples berupa data yang akan digunakan untuk membangun sebuah tree yang telah diuji kebenaran dan samples yang merupakan field - field data yang dapat mengunakan sebagai parameter dilakukan klasifikasi data.

Algoritma dasar dari C4.5 adalah sebagai berikut:

a) Pohon yang dihasilkan berupa pohon terbalik

b) Pada tahap awal, semua contoh training adalah akar

c) Atribut adalah kategori

d) Contoh di partisi secara berulang berdasarkan atribut yang dipilih

e) Atribut tes dipilih dari data heuristic atau pengukuran statistik

f) Tahapan algoritma C4.5 adalah sebagai berikut:

1. Siapkan data training

2. Pilih atribut sebagai akar

Untuk memilih atribut akar, didasarkan pada nilai Gain tertinggi dari atribut-atribut yang ada. Untuk mendapatkan nilai Gain, harus ditentukan terlebih dahulu nilai Entropy. 
Rumus Entropy:

$$
\operatorname{Entropy}(S)=\sum_{i=1}^{n}-p i * \log _{2} p i
$$

$S \quad=$ Himpunan Kasus

n = Jumlah Partisi $S$

$p i \quad=$ Proporsi dari Si terhadap $S$

Rumus Gain :

$\operatorname{Gain}(S, A)=\operatorname{Entropy}(S)-\sum_{i=1}^{n} \frac{\left|S_{i}\right|}{|S|} * \operatorname{Entropy}\left(S_{i}\right)$

$S=$ Himpunan Kasus

$A=$ Atribut

$n=$ Jumlah Partisi Atribut

$|\mathrm{Si}|=$ Jumlah Kasus pada partisi ke- $i$

$|\mathrm{S}|=$ Jumlah Kasus dalam $S$

Decission Tree atau Pohon Keputusan adalah struktur sederhana yang dapat digunakan sebagai pengklasifikasi. Referensi penting dalam pengerjaan aslinya adalah Classification and Regression Tree oleh [1].

Pada pohon keputusan, masing-masing node internal (non-leaf) merepresentasikan sebuah variabel atribut (atribut prediksi atau fitur) dan masing-masing cabang merepresentasikan satu keadaan dari variabel ini. Masing-masing dari tiga daun (leaf) menspesifikasikan nilai yang diharapkan dari kelas variabel (variabel yang akan di prediksi). Aspek penting dari prosedur untuk membuat pohon keputusan adalah pemisahan kriteria (split criterion) termasuk kriteria untuk membuat cabang dan kriteria terakhir (stop criterion), kriteria yang digunakan untuk menghentikan pencabangan.

Pohon keputusan dibuat menggunakan himpunan dari data yang digunakan sebagai data pembelajaran (training dataset). Himpunan yang berbeda yang disebut test dataset dilakukan menguguji untuk mengecek model.

Pohon keputusan menawarkan banyak keuntungan, antara lain : a) Fleksibilitas untuk berbagai tugas data mining, seperti klasifikasi, regresi, clustering dan seleksi fitur.

b) Cukup jelas dan mudah diikuti (ketika dipadatkan).

c) Fleksibilitas dalam menangani berbagai input data: nominal, numerik dan tekstual.

d) Adaptasi di dataset pengolahan yang mungkin memiliki kesalahan atau nilai-nilai yang hilang.

e) Kinerja prediktif tinggi untuk upaya komputasi yang relatif kecil

f) Tersedia dalam berbagai paket data mining melalui berbagai platform

g) Berguna untuk dataset besar (dalam kerangka ensemble).

Nä̈ve Bayes merupakan metode yang tidak memiliki aturan, nä̈ve bayes $1 \mathrm{lmu}$ komputer yang dikenal dengan teori probabilitas untuk mencari peluang terbesar dari kemungkinan klasifikasi, dengan cara melihat frekuensi tiap klasifikasi pada data training. nä̈ve bayes merupakan metode klasifikasi populer dan masuk dalam sepuluh algoritma terbaik dalam data mining, algoritma ini juga dikenal dengan nama Idiot's Bayes, Simple Bayes dan Independence Bayes [1].

Klasifikasi Bayes di dasarkan pada teorema bayes, diambil dari nama seorang ahli matematika yang juga menteri Prebysterian Inggris, Thomas Bayes (17021761). Yaitu:

$$
P(x \mid y)=\frac{P(y \mid x) P(x)}{P(y)}
$$

Keterangan:

Y : Data dengan kelas yang belum diketahui

X : Hipotesis data y merupakan suatu kelas spesifik

$\mathrm{P}(\mathrm{x} \mid \mathrm{y})$ : Probabilitas hipotesis $\mathrm{x}$ berdasarkan kondisi y (posteriori probability) 
$\mathrm{P}(\mathrm{x})$ : Probabilitas hipotesis $\mathrm{x}$ (prior probability)

$\mathrm{P}(\mathrm{y} \mid \mathrm{x})$ : Probabilitas y berdasarkan kondisi pada hipotesis $\mathrm{x}$

$\mathrm{p}(\mathrm{y}) \quad$ : Probabilitas dari y

Random Forest adalah pengklasifikasi yang terdiri dari kumpulan pengklasifikasi pohon terstruktur $\{\mathrm{h}(\mathrm{x}, \Theta \mathrm{k}), \mathrm{k}=1, \quad \ldots\}$ dimana $\{\Theta \mathrm{k}\}$ adalah vektor acak terdistribusi yang identik independen dan masing-masing pohon melemparkan unit suara untuk kelas paling populer di input $\mathrm{x}$, [5].

Random forest merupakan pengembangan dari Algoritma C4.5 (decision tree) dengan menggunakan beberapa decision tree, dimana setiap decision tree telah dilakukan training menggunakan sampel individu dan setiap atribut dipecah pada tree yang dipilih antara atribut subset yang bersifat acak.

Dan dalam mengembangkan, sejalan dengan bertambahnya dataset, maka tree pun ikut berkembang. Penempatan tree yang saling berjauhan membuat apabila terdapat tree disekitar tree $x$ berarti pohon tersebut merupakan perkembangan tree $x$ [4].

Rapid Miner merupakan perangkat lunak yang dibuat oleh Dr. Markus Hofmann dari Institute of Technology Blanchardstown dan Raif Klinkenberg dari rapid-i.com dengan tampilan GUI (Graphical User Interface) sehingga memudahkan pengguna dalam menggunakan perangkat lunak ini. Perangkat lunak ini bersifat open source dan dibuat gunakan bahasa java dibawah lisensi GNU Public License dan Rapid Miner dapat dijalankan disistem operasi manapun. Menjadi digunakan Rapid Miner, tidak dibutuhkan kemampuan koding khusus, karena semua fasilitas disediakan. Rapid Miner dikhususkan untuk penggunaan data mining.
Validasi adalah proses mengevaluasi akurasi prediksi dari sebuah model, validasi mengacu untuk mendapatkan prediksi dengan digunakan model ada kemudian membandingkan hasil yang diperoleh dengan hasil yang diketahui [3].

Mengevaluasi akurasi dari model klasifikasi sangat penting, akurasi dari sebuah model mengindikasikan kemampuan model tersebut untuk memprediksi class target [6].

Untuk mengevaluasi model digunakan metode confusion matrix, dan kurva ROC (Receiver Operating Characteristic). Confusion matrix memberikan rincian klasifikasi, kelas yang diprediksi akan ditampilkan di bagian atas matrix dan kelas yang diobservasi ditampilkan di bagian kiri [3]. Evaluasi model confussion matrix menggunakan tabel seperti matrix dibawah ini:

Tabel 1. Matrik Klasifikasi untuk Model 2 Class

\begin{tabular}{|c|c|c|c|}
\hline \multirow{3}{*}{ Classification } & \multicolumn{3}{|c|}{2 Class } \\
\hline & \multicolumn{3}{|c|}{ Predicted Class } \\
\hline & & Class $=$ Yes & Class $=$ No \\
\hline \multirow{4}{*}{$\begin{array}{l}\text { Observed } \\
\text { Class }\end{array}$} & Class & (True Positive) & (False Negative) \\
\hline & Yes & TP & FN \\
\hline & Class & (False Positive) & (True Negative) \\
\hline & No & FP & TN \\
\hline
\end{tabular}

Akurasi dapat dihitung dengan menggunakan rumus berikut:

Accurasy $=\frac{T P+T N}{T P+T N+F P+F N}$

TP : Jumlah kasus positif yang diklasifikasikan sebagai positif

FP : Jumlah kasus negatif yang diklasifikasikan sebagai positif

TN : Jumlah kasus negatif yang diklasifikasikan sebagai negatif

FN : Jumlah kasus positif yang diklasidikasikan sebagai negatif

Kurva ROC banyak digunakan untuk menilai hasil prediksi, kurva $R O C$ adalah 
teknik untuk memvisualisasikan, mengatur, dan memilih pengklasifikasian berdasarkan kinerja mereka [3].

Kurva $R O C$ adalah tool dua dimensi yang digunakan untuk menilai kinerja klasifikasi yang menggunakan dua class keputusan, masing-masing objek dipetakan ke salah satu elemen dari himpunan pasangan, positif atau negatif. Pada kurva ROC, TP rate diplot pada sumbu $\mathrm{Y}$ dan $\mathrm{FP}$ rate diplot pada sumbu X.

Untuk klasifikasi data mining, nilai AUC dapat dibagi menjadi beberapa kelompok [3].
a. $0.90-1.00=$ Excellent Classification
b. $0.80-0.90=$ Good Classification
c. $0.70-0.80=$ Fair Classification
d. $0.60-0.70=$ Poor Classification
e. $0.50-0.60=$ Failur

The Area Under Curve (AUC) dihitung untuk mengukur perbedaan performasi metode yang digunakan. AUC dihitung menggunakan rumus:

$\theta^{r}=\frac{1}{m n} \sum_{j}^{n}=1 \sum_{i}^{m}=1 \psi\left(x i^{r}, x j^{r}\right.$

Dimana

$\psi(X, Y)= \begin{cases}1 & Y<X \\ \frac{1}{2} & Y=X \\ 1 & Y>X\end{cases}$

$\mathrm{X}=$ Output Positif

$\mathrm{Y}=$ Output Negatif

\section{METODE PENELITIAN}

Metode penelitian menjelaskan jenis penelitian yang digunakan dalam penelitian ini adalah model penelitian eksperimen. Penelitian ini bertujuan untuk melakukan perbandingan dan evaluasi pada algoritma klasifikasi data mining.

Penelitian eksperimen ini menekankan pada teori-teori yang sudah ada. Pada penelitian ini, jenis penelitian yang diambil adalah eksperimen komparatif, ini dilandasi oleh kerangka pemikiran pemecahan masalah seperti pada gambar 1 .

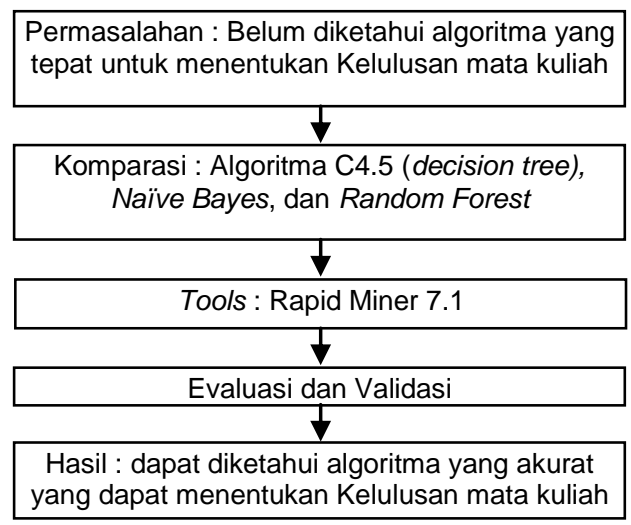

\section{Gambar 1. Kerangka Pemikiran Pemecahan Masalah}

\section{Langkah- Langkah Penelitian}

Penelitian ini dilakukan dengan menjalankan beberapa langkah proses penelitian yaitu:
a. Pengumpulan data
b. Pengolahan awal data
c. Pengukuran penelitian
d. Analisa komparasi hasil

\section{HASIL DAN PEMBAHASAN}

\section{A. Pengumpulan Data}

Mengumpulkan data membahas hasil peneliti bersumber dari Absensi mata kuliah Algoritma dimana penulis sebagai Dosen pengajar. Data merupakan hasil pemeriksaan terhadap 87 mahasiswa. Pada data ini terdiri dari 12 atribut. 
Tabel 2. Atribut Dataset

\begin{tabular}{cll}
\hline No & \multicolumn{1}{c}{ Atribut } & \multicolumn{1}{c}{ Tipe } \\
\hline 1. & NPM & Integer \\
2. & Nama & Polynominal \\
3. & Jenis_Kelamin & Binominal \\
4. & Jenjang & Polynominal \\
5. & Prog_Studi & Polynominal \\
6. & Mata_Kuliah & Polynominal \\
7. & Kehadiran & Integer \\
8. & Tugas & Integer \\
9. & UTS & Integer \\
10. & UAS & Integer \\
11. & Nilai & Real \\
12. & Status & Binominal \\
\hline
\end{tabular}

\section{B. Pengolahan Data Awal}

Dalam pengujian ini menggunakan rapid miner dengan operator 10-fold crossvalidation untuk mendapatkan hasil accuracy dan AUC pada setiap algoritma yang diuji menggunakan dataset mahasiswa.

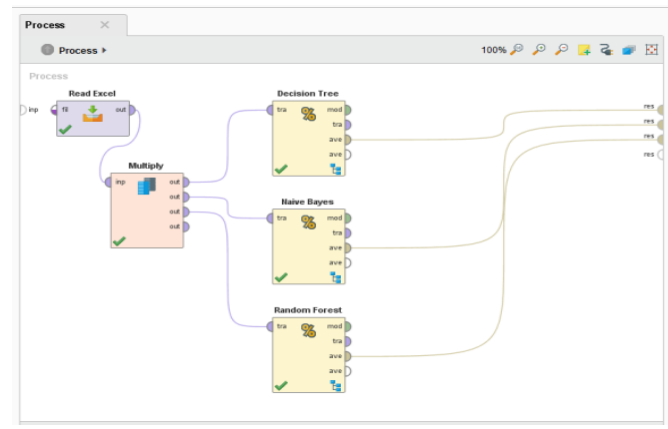

Gambar 3. Desain Model Komparasi Algoritma Klasifikasi Decision Tree, Naïve Bayes, dan Random Forest

\section{Pengukuran Penelitian}

Sedangkan Confution Matrix guna mengukur tingkat akurasinya, yang menghasilkan nilai tertinggi dari algoritma C4.5 (Decision Tree), yaitu sebesar 98.89 $\%$, gambar 4 berikut:

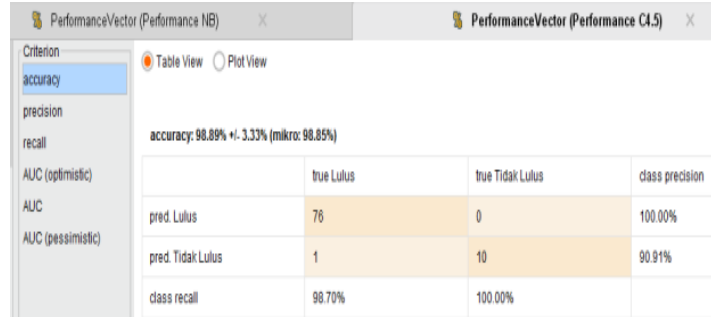

Gambar 4. Nilai Akurasi algoritma C4.5

Tabel 3. Akurasi dari Semua Algoritma Klasifikasi

\begin{tabular}{cc}
\hline & $\begin{array}{c}\text { Confusion Matrix } \\
(\boldsymbol{\%})\end{array}$ \\
\hline Decision Tree $(\mathrm{C} 4.5)$ & 98.89 \\
Naïve Bayes & 96.67 \\
Random Forest & 95.56 \\
\hline
\end{tabular}

Selanjutnya Grafik ROC (Receiver Operating Characteristic) dari algoritma C4.5 adalah sebgai berikut Gambar 5 .

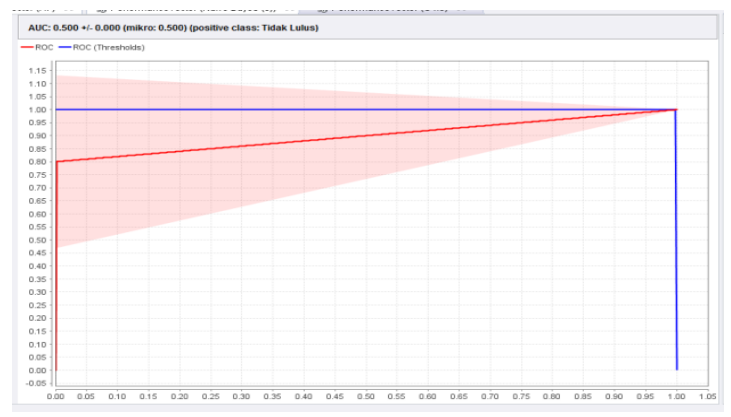

\section{Gambar 5. Grafik ROC (Receiver Operating Characteristic)}

Berdasarkan hasil evaluasi pada table 3, dapat dilihat bahwa algoritma yang paling baik digunakan untuk dataset ditentukan lulusan mata kuliah algoritma adalah Decision Tree (C4.5). selanjutnya dilakukan pengujian perbandingan antara masing-masing variabel yang didapat dengan menggunakan pengujian t-test. Gambar 6. 


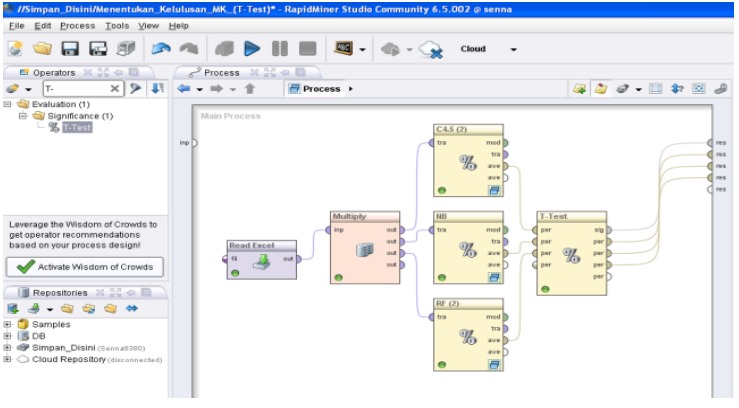

Gambar 6. T-Test

Hasil dari T-Test yang telah dilakukan, tersaji dalam gambar 7 dibawah ini :

T-Test Significance

\begin{tabular}{|l|l|l|l|}
\hline & $0.978+1 / 0.044$ & $0.956+1-0.054$ & $0.054+1-0.056$ \\
\hline $0.978+1-0.044$ & & 0.491 & 0.454 \\
\hline $0.956+1-0.054$ & & & 0.956 \\
\hline $0.055+1-0.056$ & & & \\
\hline
\end{tabular}

Frobabilities for random values with the same result

Bold values are smallet than alphin=0.050 which indicates a probabably sigruificant differencee between the actual mean values!

\section{Gambar 7. Hasil T-Test}

\section{Model}

Melalui dataset yang disajikan pada table 1 diatas, maka dapat di buat sebuah model pohon keputusan dengan menggunakan Rapid Miner 6.5, berikut adalah pohon keputusan yang dihasilkan dari algoritma decision tree dapat dilihat pada gambar 8 :

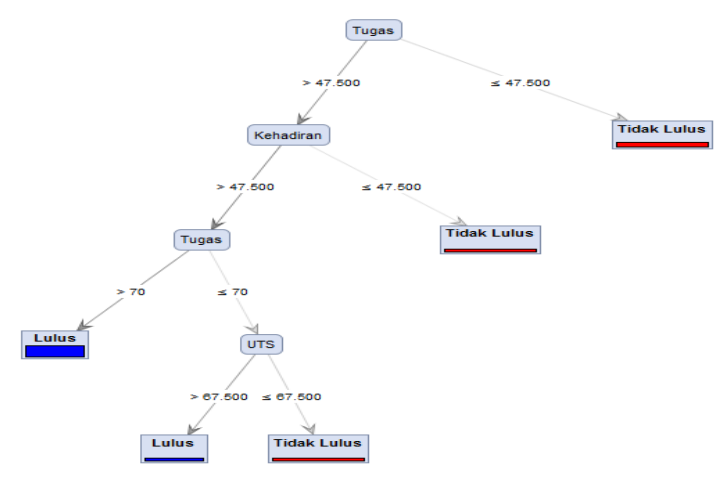

Gambar 8. Pohon Keputusan

Dari hasil klasifikasi dengan menggunakan Algoritma C4.5, maka didapat rule sebagai berikut Gambar 9 :

\section{RuleModel \\ if Tugas $>72.500$ then Lulus $(64 / 0)$ \\ if Tugas $\leq 47.500$ then Tidak Lulus $(0 / 13)$ \\ if UTS $>67.500$ then Lulus $(6 / 0)$ \\ else Tidak Lulus (0/3) \\ correct: 86 out of 86 training examples.}

\section{Gambar 9. Rule pohon Keputusan}

Berdasarkan hasil evaluasi pada rule pohon keputusan, dapat dilihat bahwa algoritma yang paling baik digunakan untuk data ditentukan lulusan mata kuliah Algoritma di Universitas Budi Luhur. selanjutnya dilakukan pengujian perbandingan antara masing-masing variabel yang didapat dengan menggunakan pengujian. Gambar 10 .

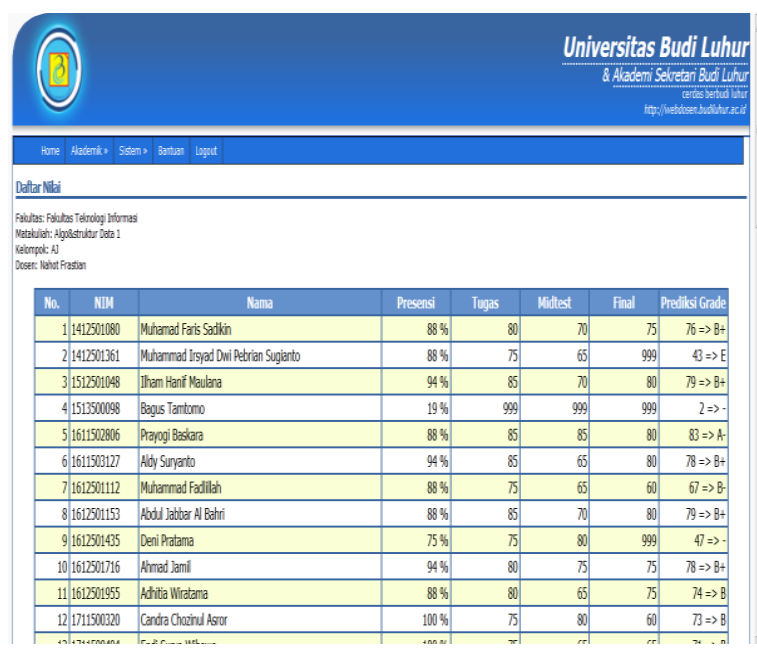

\section{Gambar 10. Penilaian mata kuliah} Algoritma Universitas Budi Luhur

\section{SIMPULAN}

Bahwasanya hasil pengujian dan analisis menjadi tujuan untuk mengetahui antara model algoritma $\mathrm{C} 4.5$, Naive Bayes dan Random Forest yang memiliki akurasi paling tinggi untuk ditentukan lulusan mata kuliah algoritma. Hasil perbandingan antara C4.5, Naive Bayes dan Random 
Forest diukur tingkat akurasinya menggunakan pengujian Confusion Matrix dan Kurva ROC. Berdasarkan hasil pengukuraan tingkat akurasi kedua algoritma tersebut, diketahui bahwa nilai akurasi C4.5 (decision tree) adalah 98.89\% dan nilai $A U C$ adalah 0.500 , selanjutnya nilai akurasi Naive Bayes $97.67 \%$ dan nilai $A U C$ adalah 2.000, sedangkan nilai akurasi Random Forest adalah 96.56\% serta nilai UAC adalah 2.000. Dapat disimpulkan bahwa dengan menggunakan model C4.5 (decision tree) lebih tinggi tingkat akurasinya, menjadi meningkat akurasi sebesar $2.22 \%$.

\section{DAFTAR PUSTAKA}

[1] Bramer, M.(2007). Principles of Data Mining London: Springer Clark. L.A., Kochanska, G., \& Ready, R. (2000). Mothers' personality and its interaction with child temperament as predictors of parenting behavior. Journal of Personality and Social Psychology, 79, 274-285.
[2] Fawcett, T. (2006). An introduction to ROC analysis. Pattern Recognition Letters, 27(8), 861-874.

[3] Gorunescu, F. (2011). Data Mining: Concepts, Models and Techniques. Berlin: Springer.

[4] Jang, J. S., Sun, C. T., dan Mizutani, E. (1997). Neuro-Fuzzy and Soft Computing : A Computational Approach to Learning and Machine Intelligence. New Jersey: Prentice Hall.

[5] Khan, I. A., dan Choi, J. T. (2014). An Application of Educational Data Mining (EDM) Technique for Scholarship Prediction. International Journal of Software Engineering and Its Applications, 8(12), 31-42.

[6] Vercellis, C. (2009). Business Intelligence. United John Wiley and Sons. 